\title{
Potential pitfalls of "specialized" primary care
}

I t basically boils down to avoiding two things: inadvertently misleading patients or providing a lower standard of care. As more general practitioners venture into areas once belonging solely to medical specialists, these appear to be the dominant bugaboos.

"There are two things that cannot be allowed to happen," says Dr. Andrew Padmos, chief executive officer of the Royal College of Physicians and Surgeons. "Patients should not be confused by the signage in a doctor's office. And you cannot have two different standards within a particular area of medical practice."

Though Canada lacks formal accreditation and appraisal processes for general practitioners with special interests, it may be inching toward some measure of certification or national standards for determining when physicians have the competence to declare a focused practice.

In fact, some jurisdictions have taken measures to ensure that patients aren't confused about their doctor's qualifications and that a family physician who performs a specialized service is just as capable in that area as a certified specialist.

On the clear signage front, Ontario appears to have taken the lead. The province's government, in consultation with the College of Physicians and Surgeons of Ontario, has established rules that create a "framework for physician communications with the public to ensure that qualifications and training are conveyed in a clear, accurate and consistent manner" (www.cpso.on.ca/uploaded Files/policies/publications/dialoguearchives /dialogueissues/Dialogue_Iss4_2010.pdf).

A doctor with a focused practice who isn't a certified specialist cannot, for instance, have a card that reads "General Practitioner-Anesthesia." Rather, it would have to be "Dr. A, Family Medicine, practising in anesthesiology."

"This is intended to ensure consistency in advertising and promotional materials, and that descriptive terms are not mistaken for formal specialization

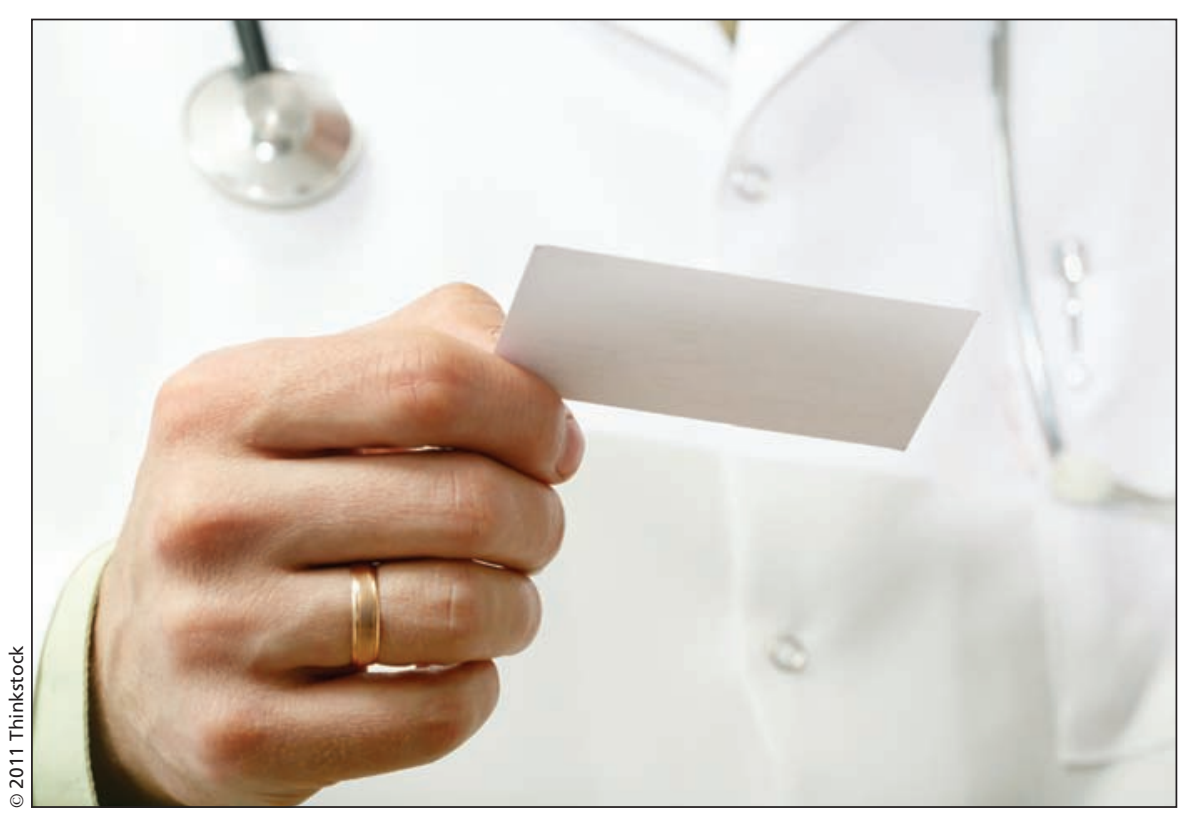

Ontario family physicians are required to follow rules governing the language on advertising and promotional materials so that areas of focus aren't confused for formal specializations or sub-specializations.

or sub-specialization," the paper states.

As for ensuring that specialized general practitioners actually possess the education and skills needed to perform well in their areas of interest, that is mostly left to hospitals and the doctors themselves, according to Susan Prins, director of communications for the College of Physicians and Surgeons of British Columbia.

"The College's role is to review physicians' education, qualifications and practice experience and determine whether they meet the registration requirements for practising medicine in the province. The College assumes that an ethical physician is only going to practise within his/her scope of practice — that which he/she has demonstrated expertise in based on academic qualifications and required training," Prins writes in an email. "The College does not credential physicians for specific procedures (such as C-sections) nor does it grant hospital privileges. These are decisions made by the hospitals and health authorities."

A family doctor who wants to frequently perform a particular procedure, such as a caesarean section, in a hospital setting would have to apply to the hospital to receive expanded privileges. If a review of relevant documents - diplomas, training certificates, letters of recommendation — indicates that a physician is qualified to perform a procedure, a hospital committee in charge of credentialing will decide whether to send a recommendation to that effect to a body with the authority to grant hospital privileges, such as the medical advisory committee of a regional health authority.

That task may soon be easier as the College of Family Physicians of Canada is contemplating the creation of a new standard of certification for focused practices that indicates whether a physician has additional skills in a particular area, such as geriatric or palliative care.

"At this stage, we are at the level of giving these groups of physicians a home in which they can meet and provide education for themselves," says Dr. Rob Boulay, the college's president, referring to its "Section of Family Physicians with Special Interests or Focused Practices."

"For the next step for some of these 
groups, we may want to have what we would call a certificate of added competence," says Boulay. "The certificates could be residency-based or based on training programs. We are also exploring ways in which family physicians could achieve these certificates through a practice-based route."

If Canadian general practitioners continue to branch out and gain competence in more areas typically associated with specialists, it may be the professional bodies of those medical specialties that call for more accountability, if the experience in the United Kingdom is any indication.

In 2000, the National Health Service introduced the concept of the general practitioner with a special interest, or GPwSI, to relieve pressure on its secondary care system. The implementation of this new type of practice, however, quickly came under criticism.

"The implementation of GPwSI services across the UK has been haphazard and unstructured with little clear guidance on accreditation and governance," according to the British Association of Otorhinolaryngologists Head and Neck Surgeons (www.entuk.org /courses/pdf/GPwSI). The paper went on to suggest that general practitioners providing ear-nose-throat services should have to apply for accreditation every three years, maintain evidence of continuing professional development and have their knowledge and skills reviewed on a regular basis.

There was a similar call for national accreditation and appraisal processes for general practitioners with a special interest in respiratory medicine. "There is an increasing awareness by government authorities, and by healthcare professionals and their professional bodies, that [general practitioners with a special interest] need to be accredited and regularly appraised in order to provide high quality services to patients," according to a UK General Practice Airways Group working party (Prim Care Resp J 2007;16:182-7).

The National Health Service did eventually produce national guidelines for the accreditation of general practitioners and pharmacists with special interests (www.pcc.nhs.uk/uploads /pwsis/january_09/improved_quality_of _care_p3_accreditation.pdf). They recommend that individuals be accredited based on a process to ensure that they demonstrate an appropriate level of skill, that they understand their new roles and that they make appropriate mentoring arrangements. The guide- lines recommend that the specialized services themselves also be accredited, a process that would include defining referral criteria and describing support infrastructure, including staff and equipment that would enable the delivery of the service.

"A rigorous and fair form of accreditation, which can be followed across the country, will help to ensure that individual clinicians have the combination of training and experience that will enable them to safely take on their new roles," the guidelines state. "The places in which they work should be resourced and governed to deliver high quality services, at least as good as those that were traditionally provided in the acute sector." - Roger Collier, CMAJ

CMAJ 2011. DOI:10.1503/cmaj.109-4044

Editor's note: Third of a three-part series

Part I: The changing face of family medicine (www.cmaj.ca/lookup /doi/10.1503/cmaj.109-4036).

Part II: A comprehensive view of focused practices (www.cmaj.ca /lookup/doi/10.1503/cmaj.109-4040). 